\title{
Políticas públicas e redes de apoio aos migrantes haitianos, em pequeno município do Rio Grande do Sul, Brasil
}

\author{
Public policies and support networks to \\ haitian migrants, in a small municipality in \\ Rio Grande do Sul, Brazil
}

\author{
Ivandro Carlos Rosa ${ }^{a}$ \\ (1) https://orcid.org/0000-0003-0965-9189 \\ Margarita Rosa Gavíria Mejía \\ (1) https://orcid.org/0000-0002-1522-3464 \\ Eduardo Périco ${ }^{a}$ \\ (D) http://orcid.org/0000-0002-2926-6246
}

Resumo: A migração de haitianos para o Brasil criou desafios públicos e privados para pequenos municípios. Avaliamos como as políticas públicas, empresas contratantes e as redes de apoio atenderam às necessidades dos migrantes, no município de Poço das Antas (RS). O método é de pesquisa multissituada, com questionários semiestruturados e busca de dados em empresas e órgãos públicos. Entre as interações, destaca-se o atendimento nas redes públicas de saúde, na área de educação infantil e na assistência social municipal.

Palavras-chave: Migrações. Mobilidade. Pequenas cidades. Políticas públicas.

\begin{abstract}
The migration of Haitians to Brazil has created public and private challenges for small municipalities. We assessed how public policies, hiring companies and support networks met the needs of migrants in the municipality of Poço das Antas (RS). The method is multi-situated research, with semi-structured questionnaires and search for data in companies and public agencies. Among the interactions, it is highlighted the public health networks, the area of early childhood education, and the municipal social assistance.
\end{abstract}

Keywords: Migration. Mobility. Small cities. Public policies. 


\section{Introdução}

N a contemporaneidade, as pequenas cidades também são afetadas por competições em investimento, por novas economias industriais e por mudanças nas pressões do mercado, e os imigrantes desempenham um papel importante nesse processo de mudança. Conforme Schiller e Çagar (2011), a economia neoliberal atinge tanto as grandes cidades quanto as pequenas. E os imigrantes se incorporam a elas, conforme as oportunidades que a cidade lhes oferece e que variam de acordo com o contexto.

O processo migratório de haitianos para o Brasil é estimulado, em parte, pela abertura de fronteiras brasileiras em 2010, em contraposição ao fechamento de fronteiras nos países europeus e nos Estados Unidos. Também influencia essa mobilidade a imagem, na época, do Brasil como país acolhedor, rico em oportunidades, num contexto histórico em que é selecionado para sediar a Copa do Mundo de 2014 e as Olimpíadas de 2016. A análise das representações sociais que impulsionaram a mobilidade dos imigrantes para o Brasil revela a imagem de um país rico, poderoso, estável economicamente, com melhores condições de vida do que no país de origem; chegar ao Brasil se tornou uma espécie de sonho americano (Mejía e Cazarotto, 2017). Para a construção dessa imagem, contribuíram ações internacionais nas quais o Brasil se projetou como protagonista de ações solidárias com povos em situações de vulnerabilidade, como no Haiti, enquanto o Brasil tem interesse em conquistar ampla representação internacional e destacar-se como potência latino-americana (Almeida, 2012).

O intenso fluxo migratório de haitianos para o Brasil foi estimulado também pela política migratória do governo brasileiro. Em janeiro de 2012, através do Conselho Nacional de Imigração (CNIg), o Brasil aceita a entrada de haitianos e cria um visto especial para eles, o visto humanitário, concedido àqueles que não tinham antecedentes penais. $\mathrm{O}$ visto humanitário outorgado aos haitianos permite-lhes requerer CPF e 
Carteira de Trabalho, documentação necessária para ingressar no mercado de trabalho (Mejía e Simon, 2015). Nesse sentido, como diz Nieto (2014), as políticas migratórias brasileiras marcaram a evolução dessa migração. Nos termos de Jardim (2017), os documentos oficiais interferem no trânsito dos migrantes.

Gestando uma dinâmica geopolítica que contrasta com o processo migratório europeu do final do século XIX e início do XX, na região, quando a migração se dava por grupos familiares em busca de terras para o cultivo de subsistência, os imigrantes haitianos que transitam pela região desde 2012 chegam ao Vale do Taquari (RS), sendo a grande maioria formada por homens, atraídos por ofertas de emprego de empresários da região que se deslocam até Brasileia, cidade fronteiriça do Brasil com a Bolívia, para negociar a vinda deles para o Estado do Rio Grande do Sul, mais precisamente para o Vale do Taquari, buscando resolver a falta de mão de obra em fábricas de processamento de carnes e laticínios e na construção civil. Esse fluxo começa tendo como agente fomentador empresas privadas e cooperativas. A participação dos setores públicos governamentais e não governamentais de ordem municipal, estadual ou nacional se dá através do reconhecimento dos migrantes como sujeitos de direitos perante a legislação brasileira. Assim, uma vez estabelecidos nas cidades onde são contratados para trabalhar, recebem das autoridades municipais assistência social básica, nos setores de saúde e educação (Mejía e Simon, 2015).

O Brasil em 2014 entra em crise e muda o olhar sobre os migrantes. O desemprego nos anos seguintes bate recordes históricos (IBGE), e as vagas de emprego são disputadas, as empresas não estimulam mais a contratação de migrantes estrangeiros. A única forma possível de mobilidade é por meio de redes de apoio como familiares e amigos, que passam a apoiar os recém-chegados até conseguirem emprego e sua autonomia financeira. Muitos desistem do Vale do Taquari e migram para outros Estados ou países da América, como Chile, em rota migratória para os Estados Unidos da América. As mudanças na economia brasileira, cinco 
anos após a chegada das primeiras levas de imigrantes haitianos ao Vale do Taquari, têm dificultado o acesso a recursos financeiros para melhorar suas condições de vida e as dos membros da família no Haiti, através da remessa de dinheiro.

Quando tratamos de seres humanos, a complexidade é uma variável a ser considerada, estamos nos referindo a pessoas envolvidas com problemas afetivos, que têm crenças, credos, princípios de sobrevivência e de coexistência. O sistema, a estrutura, que envolve seres humanos foge do certo, alinhado e coerente. O grau de incerteza está sempre presente, obrigando-nos a avaliar os problemas com um olhar externo, sem as influências de nossas convicções anteriores, viciadas, separando o que é real do imaginário (Morin, 2007). O imigrante constituiu força de trabalho e presença provisória, sendo uma situação aceitável para os nacionais e para os próprios migrantes, pois o caráter provisório da migração que, segundo o mesmo autor, muitas vezes, torna-se permanente, é o que torna a convivência tolerável (Sayad, 1998).

Nos municípios do Vale do Taquari, a estrutura populacional e os recursos disponíveis para acolher esses migrantes não são iguais. Também diferem os arranjos de cada administração municipal para recebê-los, bem como diferem as organizações não governamentais, religiosas e laicas, que desenvolvem programas de apoio aos novos migrantes. $O$ Vale do Taquari é composto, segundo a Fundação de Economia e Estatística (FEE, 2018), por 36 municípios, na divisão dos Coredes (Conselhos Regionais de Desenvolvimento do Estado do Rio Grande do Sul), que, aqui na região, denomina-se Codevat (Conselho de Desenvolvimento do Vale do Taquari). Ainda de acordo com a Fundação de Economia e Estatística (FEE, 2018), no Estado, são 26 conselhos regionais. As municipalidades que compõem o Codevat têm perfis heterogêneos, não só em termos de densidade populacional e infraestrutura econômica, mas também cultural. Diferem no que diz respeito às influências culturais marcadas pela origem migratória europeia, alguns municípios com o predomínio 
de descendentes alemães, outros, de descendentes de migrantes italianos (Knob e Knob, 1998).

Utilizando Poço das Antas como estudo de caso, pretendemos abordar a dinamização dos espaços públicos e privados em uma pequena cidade do Vale do Taquari (RS), a partir da intensificação da migração haitiana desde 2014, analisando o planejamento de políticas públicas que atingem essa população.

\section{Metodologia}

Município de Poço das Antas - perfil e indicadores

Segundo o IBGE (2020), o município de Poço das Antas (Figura 1) possui população estimada de 2.101 habitantes, em levantamento anterior, 880 pessoas residiam na área urbana e 1.202 habitantes na área rural do município (IBGE, 2019). Na caracterização por gênero (IBGE, 2018), eram 1.142 homens e 1.072 mulheres. Observamos que a população evoluiu lentamente desde o último censo IBGE (2010), que registrava 2.017 habitantes, acréscimo de 4,00\% em uma década.

No perfil social, possui índice IDESE 2016 (Índice de Desenvolvimento Socioeconômico) de 0,76, ranqueado na 203a posição no Estado do Rio Grande do Sul. Comparando o IDESE dos anos 2007 (0,7213) e 2016 $(0,7606)$, percebe-se que houve um aumento/evolução de 5,17\%. Quanto aos indicadores de renda, segundo o IBGE (2017), o PIB (Produto Interno Bruto) foi de $R \$ 71.264 .720,00$, enquanto o PIB anual per capita, segundo o IBGE (2017), foi de $\mathrm{R} \$ 33.743,00$. Quanto à faixa de remuneração média, segundo o IBGE (2018), 55,38\% dos trabalhadores ganham entre 1,51 a 2,00 salários mínimos. A renda domiciliar per capita, conforme o IBGE (2010), é de R\$ 806,97. O índice Gini da Renda Familiar 1991-2010 (GINI-RS) é 0,547. De acordo com os indicadores de educação (IBGE, 2010), a taxa de analfabetismo é de 2,6\%. 
Figura 1. Localização de Poço das Antas na região, Brasil e América.

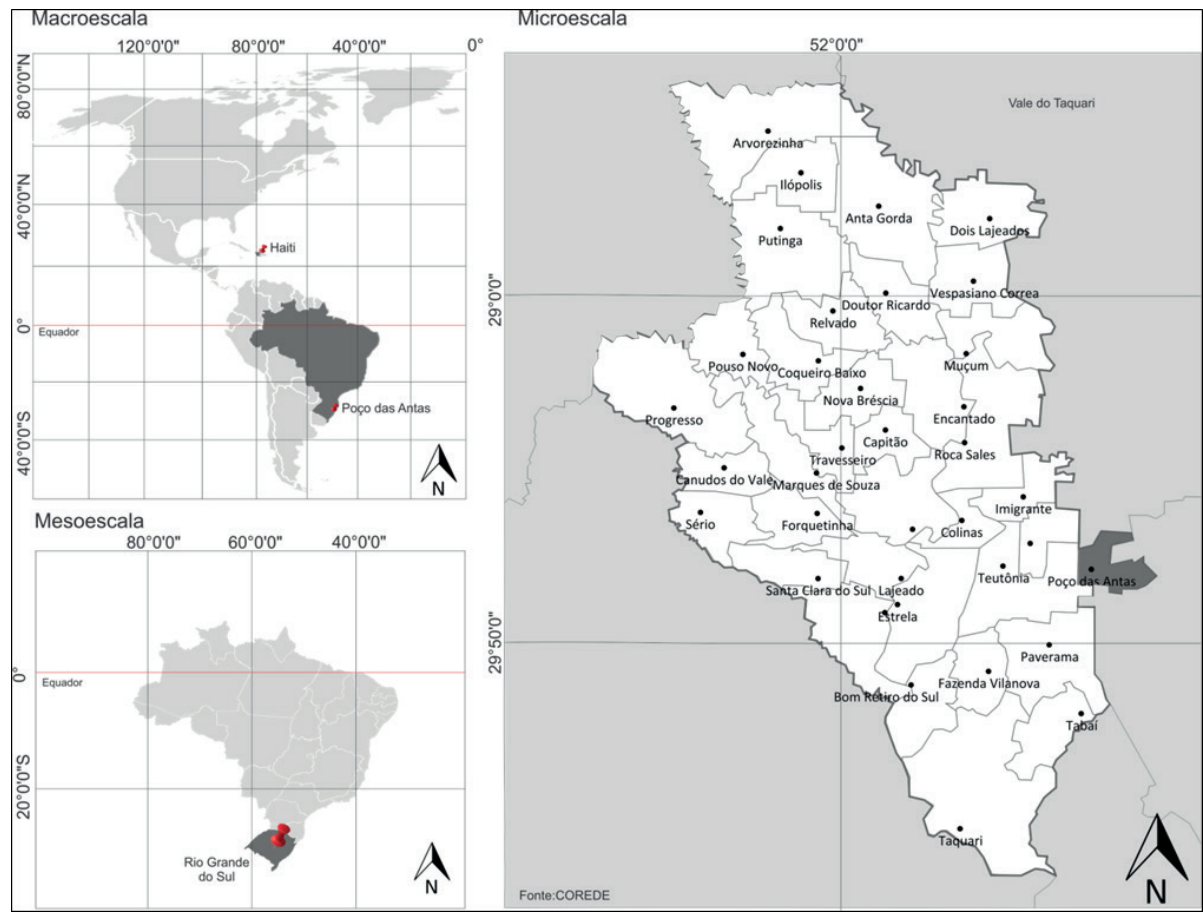

Fonte: Elaborada pelos autores (2020).

\section{Coleta de dados}

Tomou-se como eixo de referência na pesquisa os espaços sociais ocupados pelos haitianos no município de Poço das Antas, selecionado como ponto de partida por se tratar de um município com maior percentual proporcional de população haitiana em comparação com os demais municípios da região. Para atingir os objetivos propostos, além da pesquisa bibliográfica e documental para obter informações que contribuíram para a construção dos dados, foi realizada uma pesquisa etnográfica no município de Poço das Antas. Essa abordagem etnográfica multissituada permite estudar um fenômeno social que não pode ser abordado pelo estudo de apenas um local, mas de vários pontos onde há interação, 
setores de acolhimento, trabalho, trocas culturais. O objetivo principal da pesquisa multissituada é seguir pessoas, conexões, associações e relações através do espaço (Marcus, 2001). Ainda conforme o autor, o emprego desse método requer um campo disperso no qual o pesquisador transita e coleta informações que buscam dar conta das ligações existentes entre os diferentes lugares componentes do objeto de estudo. Foram utilizadas técnicas de pesquisa aplicadas em Estudos Sociais, como entrevistas dirigidas, observação, diários de campo e análises de documentos.

Iniciou-se a pesquisa indagando os órgãos públicos acerca das ações desenvolvidas a partir dessa onda migratória. Pesquisaram-se registros oficiais dos atendimentos em saúde e educação, que são as principais demandas dos migrantes nessa área. Na Secretaria da Educação, buscaram-se informações relativas à inclusão dos filhos de haitianos nas escolas. Vale observar que a maioria das crianças matriculadas nas séries iniciais, filhos e filhas de haitianos em Poço das Antas, nasceu no Brasil; portanto, são brasileiras. Recentemente, chegaram crianças nascidas em outros países, portanto, também migrantes, com necessidades de inclusão mais complexas, em virtude de dificuldades com o idioma.

Foram entrevistados os profissionais encarregados de atendê-los, para identificar as principais dificuldades na atenção à saúde e à educação dos haitianos. Aprofundou-se acerca dos reflexos das dificuldades de comunicação linguística, do desconhecimento da língua portuguesa e da comunicação cultural. Junto à secretária de assistência social, foram levantadas as principais demandas dos migrantes e as medidas adotadas pelo setor público para atender a elas, bem como as possibilidades ou os limites para a inclusão nos programas brasileiros, como o Cadastro Único do governo federal (CadÚnico), que propicia uma série de benefícios assistenciais aos recém-chegados. Também se questionou a respeito dos programas implementados pelos gestores de empresas e cooperativas que trouxeram os imigrantes e providenciaram emprego e acolhimento inicial. Os espaços de produção econômica se constroem em torno das relações de trabalho, observando as condições de trabalho, as posições que ocupam, o significado desse espaço de produção para os migrantes. 
Como instrumento de coleta de dados, realizaram-se entrevistas semiestruturadas nas empresas que empregam os(as) haitianos(as), bem como com a população local (residentes no local antes da migração haitiana), com os proprietários de áreas de terra cultivadas por haitianos e também os haitianos, como forma de abordar diferentes pontos de vista, da dinâmica observada com a chegada desse novo grupo de migrantes, como laboratório de análise. Paralelamente, foram realizadas entrevistas semiestruturadas com os haitianos, para lhes indagar acerca dos limites e das possibilidades que eles têm encontrado para participar dos espaços públicos desses municípios. Os questionários das entrevistas não envolviam dados pessoais, possíveis de identificação, como nome, apenas a idade do respondente, para preservar seu anonimato. Para facilitar a organização, foram criadas três categorias de questionários identificados como sendo "L" - moradores de Poço das Antas, antes da chegada dos haitianos; o questionário "M" - migrante haitiano; o "N" — proprietário de área de terra, que a empresta para o plantio. Além da letra de identificação, também foram identificados o mês e o ano das entrevistas.

Além dessa visita do grupo, foram feitas diversas visitas e acompanhamento de atividades com secretários municipais, assistentes sociais no Centro de Referência de Assistência Social (CRAS), professores municipais, sempre com prévio agendamento.

\section{Resultados e discussão}

A contratação de haitianos em Poço das Antas iniciou pelo frigorífico de abate e processamento de carne suína. A equipe de Recursos Humanos, visando atender a uma demanda de colaboradores, num contexto de grande escassez de mão de obra na época da inauguração dessa nova planta industrial no município de Poço das Antas, buscou selecionar trabalhadores de outras regiões do país. Não obtendo êxito, buscou a contratação dos recém-chegados haitianos ao Norte do Brasil. Houve o deslocamento de representantes até Brasileia, cidade localizada na fronteira com a Bolívia. Após a seleção baseada em critérios preestabelecidos 
pela diretoria da cooperativa, seu conselho de administração e pela legislação brasileira, ocorreu a contratação do primeiro grupo de imigrantes. Segundo entrevista com responsáveis pelo setor de Recursos Humanos, a intenção era de que a contratação fosse feita em grupos menores, para facilitar a instalação e o acompanhamento do grupo em Poço das Antas.

A vinda dos haitianos trazidos pela cooperativa ocorreu em duas etapas. Após essas duas primeiras etapas de contratação pela cooperativa, houve a continuidade de contratações de haitianos, porém, através de suas próprias redes migratórias e de seus contatos familiares e profissionais. $O$ primeiro grupo chegou em ônibus locado pela empresa. Eram 42 migrantes do sexo masculino, na faixa etária de 18 a 50 anos. Segundo o encarregado do RH da Cooperativa, no dia 9/12/2013, chegou o primeiro grupo de haitianos, vindos da Brasileia. Na segunda etapa, vieram 30 homens haitianos, na faixa etária de 18 a 50 anos. Um aspecto que se destaca é que foram selecionados apenas haitianos homens. 0 critério de exclusão das mulheres era porque eles desempenhariam funções que exigem maior esforço físico. Outro critério era a escolaridade, ou seja, era selecionado quem tinha o segundo grau completo ou curso superior. Para o encarregado do setor de Recursos Humanos da cooperativa na época, era mais fácil acomodar pessoas do mesmo sexo. Eram distribuídos quatro migrantes em cada quarto com armário. Após a vinda desses dois grupos, chegaram outros, sem o transporte e a seleção prévia da cooperativa. Ao todo, foram contratados 85 trabalhadores haitianos, que partilhavam a cozinha coletiva no alojamento.

\section{Atendimento à saúde}

A saúde dos migrantes, tanto no aspecto físico como mental, deve fazer parte da sua inserção na nova casa, das novas vivências e do processo de aculturação. Ramos (2009) ressalta a necessidade de atenção com a saúde física e mental dos migrantes, como forma de atendimento das condições mínimas de acolhimento. Essas medidas também repercutem na forma como os migrantes reagem às novas regras e à nova rotina, num território desconhecido. Ao oferecer o direito fundamental à saúde 
ao migrante, procura-se prevenir o estresse, a depressão, doenças físicas e psíquicas. Em relação ao caso específico de Poço das Antas, a cooperativa, quando fez a contratação inicial dos migrantes, teve o cuidado de criar uma estrutura de acolhimento e de adaptação à realidade local, no âmbito de moradia, alimentação, saúde, bem como em termos de apoio psicológico dos novos contratados, vindos de um país caribenho, com particularidades culturais diversas. A cooperativa também acompanhou o impacto nos funcionários que residiam na região antes da chegada dos migrantes caribenhos, os que tiveram o primeiro contato com os haitianos, na convivência diária da rotina de trabalho.

$\mathrm{O}$ atendimento de saúde em Poço das Antas é feito na Unidade Básica de Saúde (UBS), situada no centro da cidade, ao lado da prefeitura municipal, que fornece atendimento básico, já que o município não possui hospital. Para essa Unidade, são direcionados os atendimentos aos pacientes com doenças que não são graves. Se precisarem de atendimento mais especializado e de exames médicos complexos, são encaminhados a outros centros especializados. Todo o atendimento médico e os medicamentos são fornecidos de forma gratuita aos pacientes, custeados pelo SUS (Sistema Único de Saúde), em convênio com a Secretaria Municipal de Poço das Antas. No Posto de Saúde atendeu, até o ano de 2019, um médico cubano, pelo programa "Mais Médicos" do governo federal. Através de convênio entre a União e os municípios, os médicos estrangeiros ocupam postos de atendimento, principalmente, em pequenas cidades, propiciando um atendimento diferenciado, chamado médico da família. Nas UBS, esses profissionais fazem o acompanhamento de pacientes com doenças como hipertensão arterial, entre outras práticas de prevenção a doenças crônicas.

O fato de o médico provir de uma ilha caribenha facilita a comunicação com os haitianos e permite dar-lhes suporte no Brasil, país continental, com ampla diversidade cultural e étnica. Os funcionários da USB demonstram ter o maior respeito pelos imigrantes, até por entender que "todos somos imigrantes em épocas diferentes, de origens diferentes". Em relação à maior dificuldade que os haitianos enfrentam na rede de atendimento à saúde, afirmam que é "a dificuldade com a língua portuguesa 
para expressar as suas mais diversas queixas". No que diz respeito à interferência cultural no atendimento às mulheres, dizem: "não teve nenhuma dificuldade por enquanto". Geralmente, elas vêm com os seus parceiros ou com outro haitiano que fala um pouco melhor o português para traduzir os seus problemas de saúde, já que essa é maior dificuldade: "muitas chegam aqui sem saber falar nada".

Quanto aos aspectos positivos destacados no atendimento de saúde dos haitianos em Poço das Antas, afirmam: que têm atenção médica e de enfermagem de graça, recebem muitas medicações da farmácia da UBS (Unidade Básica de Saúde) sem ter que pagar. Além disso, se precisar de encaminhamentos, realizar exames, entre outros procedimentos, têm os mesmos direitos que os moradores de Poço das Antas quanto à atenção primária e secundária em saúde. No final, salientam um fato que lhes chamou a atenção no atendimento aos haitianos durante o período que têm trabalhado em Poço das Antas:

Teve um paciente haitiano com múltiplas queixas somáticas do aparelho digestivo, muito difícil de compreender na hora de consultar pela dificuldade para falar português. Foi consultado inúmeras vezes, até por uma médica brasileira que trabalhou na UBS. O exame físico e os exames solicitados mostraram resultados normais. Alguns, como ele, desenvolvem transtornos de somatização causados por começar uma nova vida em um país estrangeiro e ter deixado suas famílias (filhos, esposas, esposos) lá em Haiti.

Comparando a migração haitiana com a brasileira para outros países, no caso de Genebra na Suíça, segundo Franken, Coutinho e Ramos (2010), a maioria dos migrantes brasileiros entrevistados, que estavam entre o primeiro e o terceiro ano no país europeu, apresentava sinais semelhantes aos do luto, em função das profundas mudanças psicossociais e da adaptação às normas e às regras de convivência, além de muitos apresentarem sinais de estresse e sofrimento. Ainda, segundo os autores, as mulheres sem cidadania, na Suíça, estão submetidas a uma série de dificuldades, como insegurança, o isolamento dos familiares no local de acolhimento e, muitas vezes, incompreendidas, ficam mais vulneráveis a transtornos e apresentam maior fragilidade da saúde mental. 
Em entrevista, um dos migrantes (M5-01/2020), quando perguntado sobre questões de saúde, comenta a precariedade do atendimento no Haiti, onde, segundo o entrevistado, não há um modelo (SUS - Serviço Único de Saúde) público e gratuito. Nos raros postos de saúde, o atendimento é precário e dificilmente se consegue atendimento médico, com cobrança pelos atendimentos e com poucos equipamentos. Um dos líderes dos migrantes (M6-12/2020) relata que, após sua migração, sua ex-esposa, grávida de uma outra relação, precisou de atendimento, mas não conseguiu, pois a família demorou para conseguir o dinheiro para contratar uma ambulância particular e, infelizmente, veio a óbito. Portanto, elogia o atendimento dispensado nas unidades de saúde brasileiras e a Secretária de Saúde municipal, pois, quando precisou passar por procedimento cirúrgico num braço, obteve consultas, exames, transporte e a cirurgia custeados pelo SUS. Ainda, após o procedimento, utilizou o auxílio-doença por alguns meses, até estar reabilitado e ter condições de retornar ao trabalho. Vem daí a convicção do entrevistado de que no Brasil o migrante "tem ajuda e vive bem, só que não ganha muito dinheiro, e fica difícil enviar ajuda para a família no Haiti”.

\section{Atendimento na educação}

O Centro Municipal de Educação é uma escola de Educação Infantil, de propriedade e manutenção da Secretaria Municipal de Educação, que atende os bebês que chegam com quatro meses, após a licença-maternidade das mães. Segundo o relato da diretora, atualmente, estão frequentando a escola de Educação Infantil seis alunos, filhos de haitianos, dos quais cinco são nascidos no Brasil: um em Cafelândia-PR/BR; um em Passo Fundo-RS/BR; um em Lajeado-RS/BR; dois em Teutônia-RS/BR, que é a maternidade mais próxima de Poço das Antas, já que o município não possui hospital, apenas Unidades Básicas de Saúde (UBS). Uma menina que chegou recentemente a Poço das Antas, nascida em Porto Príncipe, capital do Haiti, está com cinco anos e fala apenas espanhol. No período inicial de adaptação, ela teve dificuldades de comunicação; porém, recebeu atenção especial por parte dos professores e evoluiu 
bastante na compreensão da língua, melhorando sua integração com os colegas de escola.

Outro educandário que também atende crianças descendentes de haitianos nascidas no Brasil, porém, em menor número, é o colégio municipal Leo Pedro, que fica aproximadamente a um quilômetro do centro da cidade, no qual também estão matriculados quatro alunos, filhos de haitianos. Nesse educandário, estudam crianças nas séries iniciais do Ensino Fundamental, de primeira a quarta série primária.

\section{Atendimento de assistência social e redes de apoio}

Na perspectiva da ideia de atender ao fluxo da vida, a presença feminina leva à constituição de famílias entre a diáspora haitiana, porque é comum as mulheres engravidarem logo após a reunificação ou união familiar. A gravidez de haitianas em Poço das Antas é uma situação que revela, segundo Jardim (2017), como as políticas públicas têm se reinventado com a presença de migrantes. É uma oportunidade de descobrir "a singularidade da experiência migratória perante os equipamentos públicos (relativos à saúde e à educação) a partir de experiências relativas aos fluxos da vida" (p. 202). Na pesquisa etnográfica, observa-se que a gravidez das haitianas mobiliza os agentes de saúde. Elas recebem acompanhamento no CRAS (Centro de Referência de Assistência Social) e as consultas do pré-natal são feitas no posto de saúde. No momento do parto, as mães são encaminhadas ao hospital mais próximo, no caso, em Teutônia, que fica a 15 quilômetros de Poço das Antas.

\section{A análise da atuação em rede de agentes governamentais e não governamentais: o caso da morte do filho de um casal haitiano}

A doença e a morte de uma criança representaram uma situação que, nesta experiência migratória haitiana, mobilizou as tecnologias da 
governamentalidade que são, nos termos de Jardim (2017, p. 27), “[...] as materialidades, dinâmicas e agentes que podem ser visualizados como parte das práticas de governamentalidade das imigrações". Nesse sentido, o relato do falecimento de um bebê nascido no Brasil, portanto, brasileiro, filho de um casal de haitianos que se conheceu aqui no país, traz à luz diversos agentes e materialidades envolvidas na governamentalidade da migração haitiana na cidade de Poço das Antas.

Os migrantes buscaram suporte na rede de atendimento à saúde para uma criança de dois meses de vida, que teve problemas respiratórios. 0 fato mobilizou agentes de saúde pública em três instâncias. Primeiro, no posto de saúde de Poço das Antas; como não conseguiram controlar os sintomas da doença, a prefeitura da cidade solicitou atendimento aos agentes de saúde no hospital de referência na região (Hospital Ouro Branco), em Teutônia, transferindo o bebê na ambulância da prefeitura de Poço das Antas. Mas, como também não conseguiram resolver a situação no hospital regional, incluíram no processo de atendimento os agentes de saúde de um centro especializado na capital gaúcha, Porto Alegre, para onde o bebê foi transferido. Contudo, devido à gravidade da enfermidade, o menino faleceu. Nesse caso, a visibilidade do corpo doente depende das lógicas de territorialização da saúde e de decisões administrativas.

Ao direcionar a atenção para todos os acontecimentos em torno da doença e da morte do filho dos haitianos, percebe-se que o fato coloca em ação agentes governamentais e não governamentais. Isto é, mobiliza um sistema de serviços de atendimento público, criando, nesse episódio em particular, uma rede de apoio aos pais da criança. O migrante haitiano, em Porto Alegre, recebeu apoio do secretário da administração municipal de Poço das Antas, agente governamental que contratou os serviços de uma funerária para que fizesse o deslocamento da família da capital do Rio Grande do Sul à cidade da residência, bem como ajudou a providenciar a documentação necessária, como atestado de óbito, e fez os demais encaminhamentos burocráticos.

Uma vez em Poço das Antas, participam também da rede de apoio outros agentes, vinculados à igreja católica. Como a família era membro 
da comunidade católica da cidade, o velório e o sepultamento da criança foram realizados no cemitério católico, nas imediações do centro da cidade, com recursos financeiros do casal. O padre da igreja local conduziu, a pedido da família, o ritual religioso com orações e cânticos católicos. Acompanhou o sepultamento, além dos pais, um grupo de aproximadamente 20 haitianos que residem nas imediações, bem como outras pessoas da comunidade que se solidarizaram com a perda da criança. Como foi o primeiro caso de falecimento de migrantes, houve solidariedade e consternação por parte da comunidade local.

Após o falecimento da criança, a mãe procurou o CRAS (Centro de Referência de Assistência Social), que funciona ao lado do posto de saúde municipal, e solicitou ajuda para enfrentar o luto, nesse momento difícil da perda do filho. Diante dessa demanda, interveio a assistente social, que, ao ter conhecimento das demandas da haitiana, encaminhou-a para oficinas e grupos de apoio, que acontecem nas dependências do CRAS de Poço das Antas. A referida mãe haitiana, ao ver fotos de gelatina no CRAS, expressou seu desconhecimento acerca desse alimento. A equipe do CRAS então a convidou, após a oficina, para observar na cozinha a preparação da gelatina.

O encontro da haitiana com as mulheres brasileiras nas oficinas do CRAS motivou as participantes a utilizarem a culinária como elemento de comunicação entre as duas culturas. Os encontros se estenderam aos finais de semana, quando as anfitriãs ensinariam a mãe enlutada a preparar pratos típicos da culinária local, como a galinhada, prato de interesse da mãe haitiana, tendo em vista que sua outra filha o teria experimentado e gostado dele e queria que a mãe o preparasse em casa. Então, as vizinhas da haitiana que participaram das oficinas se juntaram numa casa, num final de semana, e prepararam, na presença da haitiana, a galinhada para que ela aprendesse. Essa situação possibilitou uma maior aproximação entre migrantes e a comunidade local.

Em Poço das Antas, foi organizada uma rede de apoio baseada nas pessoas que exerciam liderança na empresa contratante, como também na administração pública municipal, que criaram condições para a aclimatação dos migrantes. Além do auxílio e da atenção às necessidades, 
também ocorreram interações, muito importantes para a adaptação dos migrantes nesse novo território. Segundo um dos líderes do grupo de haitianos, eles foram convidados a participar de um campeonato de futebol, na praça central da cidade, inicialmente, com time formado por haitianos, contra o time da prefeitura. Depois de algumas partidas, houve a mescla de atletas haitianos e poço-antenses. Essa prática de socialização ocorre há vários anos, sempre nas terças-feiras, após o expediente de trabalho no frigorífico.

Quanto à rede de aproximação e acolhimento, destaca-se o trabalho da Secretaria de Obras, que intermediou e viabilizou o início de um sistema de plantio em terrenos particulares pelos migrantes. Ficou evidenciado no questionário respondido pelo proprietário dos lotes (N110/2019) que a motivação para dar início ao processo foi a solicitação dos funcionários da Secretaria de Obras. Após o plantio e a primeira colheita, foram disponibilizados novos lotes. Perguntado sobre como é visto o gesto de produzir alimentos fora do horário de expediente por parte dos migrantes, respondeu que sente muita admiração, pois, no início, havia uma sensação de desconfiança por parte da comunidade poço-antense em relação aos recém-chegados. Ficou evidente na entrevista que a imagem dos migrantes melhorou muito aos olhos dos proprietários das áreas, que, no início, emprestavam a terra para conhecidos, vinculados à Secretaria de Obras do município. Já na etapa seguinte, tratavam diretamente com os haitianos, através de seus líderes. Conforme o entrevistado, é uma satisfação ver a terra sendo bem cuidada e produzindo alimentos.

Em entrevista com um dos líderes do grupo de haitianos (M211/2019), que reside em Poço das Antas desde 2013 (9/12/2013), data de início do vínculo de trabalho junto ao frigorífico, o entrevistado explicou que os migrantes têm regras próprias de organização, expressas por uma sociedade criada por eles, a "Sociedade Amigos Necessitados" (SAN), que, segundo ele, orienta o trabalho e a ação do grupo de haitianos. Para todas as ações do grupo, há uma reunião (assembleia) para discutir as dificuldades e avaliar as condições de cada um dos integrantes do 
"SAN". Trata-se de um sistema de governança que funciona por grupos, que, geralmente, compartilham a mesma moradia. Esse grupo de cinco a seis componentes trabalha e cria uma dinâmica de auxílio, na qual todos serão ajudados.

Em contrapartida, quando surge uma necessidade de dinheiro para passagens de familiares ou para o envio de recurso, em volume superior à remuneração de um dos migrantes, esse grupo se reúne e faz um rateio dos custos e complementa o dinheiro, para que esse membro consiga enviar o dinheiro necessário. Essa prática é comum, quando um dos membros pretende trazer a família ou um membro da família do Haiti para o Brasil, por exemplo. Para que todos tenham garantia de auxílio, essa prática é combinada com transparência e confiança recíproca entre os membros do pequeno grupo.

\section{Referências}

ALMEIDA, Paulo Sérgio de. La política de migraciones brasileña y la migración haitiana a Brasil. International Organization for Migration, 2012. Disponível em: http://www.iom.int/ cms/en/sites/iom/home/what-we-do/migration-policy-andresearch/migration-policy-1/ migration-policy-practice/issues/october-november-2012/lapolitica-de-migracionesbrasi.html. Acesso em: 20 nov. 2018.

DATASEBRAE. Perfil das cidades gaúchas 2020. 2020. Disponível em: datasebrae.com.br/ perfil-dos-municipios-gauchos/pocodasantas. Acesso em: 29 ago. 2020.

FRANKEN, I.; COUTINHO, M. P. L.; RAMOS, N. Os impactos negativos do processo migratório internacional e os transtornos mentais comuns: um estudo com brasileiros imigrantes. [S. l.]: Universidade Aberta - Repositório Comunidade CEMRI - Centro de Estudos das Migrações e Relações Interculturais, 2010. Disponível em: file:///C:/ Users/Usuario/Downloads/Dialnet-TranstornosMentaisComunsNoContextoMigratorioI ntern-5631416\%20(1).pdf. Acesso em: 24 ago. 2020.

FUNDAÇÃO DE ECONOMIA E ESTATÍSTICA (FEE). Disponível em: http://www.arquivofee. rs.gov.br. Acesso em: 8 set. 2020.

FUNDO MONETÁRIO INTERNACIONAL (FMI). Disponível em: https:/www.imf.org/ external/index.htm. Acesso em: 6 out. 2020.

INSTITUTO BRASILEIRO DE GEOGRAFIA E ESTATÍSTICA (IBGE). Disponível em: http:// www.ibge.gov.br/home/estatistica/populacao/estimativa2017/estimativa_dou.shtm. Acesso em: 5 out. 2020. 
JARDIM, D. F. Imigração ou refugiados? Tecnologias de controle e as fronteiras. Jundiaí: Paco Editorial, 2017.

KNOB, P.; KNOB, D. Poço das Antas: primeiro lugar no ranking de alfabetização. Porto Alegre: Evangraf, 1998.

MARCUS, G. E. Etnografía en/del sistema mundo. El surgimiento de la etnografía multilocal. Alteridades, Ciudad de México, v. 11, n. 22, 2001.

MEJÍA, M. R. G.; CAZAROTTO, R. T. O papel das mulheres imigrantes na família transnacional que mobiliza a migração haitiana no Brasil. Repocs, Santa Maria, v. 14, n. 27, 2017.

MEJÍA, M. R. G.; SIMON, R. Sonhos que mobilizam o imigrante haitiano: biografia de Renel Simon. Lajeado: Univates, 2015.

MORIN, E. Introdução ao pensamento complexo. Tradução: E. Lisboa. Porto Alegre: Sulina, 2007.

NIETO, C. Migración haitiana a Brasil: redes migratorias y espacio social transnacional. Buenos Aires: CLACSO, 2014.

ORGANIZAÇÕES DAS NAÇÕES UNIDAS (ONU). Disponível em: https://brasil.un.org/pt-br. Acesso em: 6 out. 2020.

RAMOS, N. Saúde, migração e direitos humanos. Mudanças: psicologia da saúde, v. 17, n. 1, jun. 2009. Disponível em: https://www.metodista.br/revistas/revistas-ims/index. php/MUD/article/view/1924/1938. Acesso em: 25 ago. 2020.

SAYAD, A. A imigração ou os paradoxos da alteridade. São Paulo: Edusp, 1998.

SCHILLER, N. C.; ÇAGAR, A. Introduction: migrants and cities. In: SCHILLER, N. C.; ÇAGAR, A. (org.). Location migration: rescaling cities and migrants. Ithaca: Cornell University, 2011.

\section{Sobre os autores}

IVANDRo CARlos RosA - Doutor em Ciências: Ambiente e Desenvolvimento. E-mail: eng.ivandro@universo.univates.br

Margarita Rosa Gavíria Mejía - Antropóloga, doutora em Ciências. E-mail: margaritarosagaviria@gmail.com

EdUARDo PÉRICo - Doutor em Ecologia. Professor titular. E-mail: perico@univates.br 